\title{
In vitro Evaluation of Antiproliferative Effects of Self-assembling Nanoemulsion of Paclitaxel on Various Cancer Cell Lines
}

\author{
Mukta Bagul11,2, Srikanth Kakumanu1,2, Thomas Wilson ${ }^{1,2}$ and Robert Nicolosi ${ }^{1,2 *}$ \\ ${ }^{1}$ Center for Health and Disease Research - Division of NanoMedicine, Department of Clinical Laboratory and Nutritional Sciences ${ }^{2}$ \\ and the Biomedical Engineering/Biotechnology Ph.D. Program² University of Massachusetts Lowell, Lowell, MA 01854. \\ *Corresponding authors. Email: Nicolosi.Robert@yahoo.com
}

\begin{abstract}
Paclitaxel is routinely used in cancer chemotherapy to treat patients with ovarian, breast, lung, head and neck cancers. However, because of its low aqueous solubility, it's been administered as a Cremophor EL and ethanol solution, which is associated with increased toxicity and high therapeutic dose requirements. The goal of the present study was to formulate paclitaxel into a self assembling nanoemulsion (SANE) and demonstrate the effects of paclitaxel SANE formulation on the inhibition of cell proliferation in breast (80\%), colon (60\%), and pancreatic cell lines (60\%) compared to blank nanoemulsion. In addition, nanoemulsions of paclitaxel with a mean particle size of $20 \mathrm{~nm}$ dramatically reduced zeta potential and showed up to 12 fold greater apoptosis in the PL-45 pancreatic cancer cell line compared to a blank nanoemulsion. In conclusion we have developed a SANE formulation of paclitaxel having a particle size of $20 \mathrm{~nm}$ which significantly inhibited cell proliferation, dramatically reduced zeta potential and increased apoptosis by 12 -fold when compared to a blank and nanoemulsion, thus indicating the therapeutic potential for SANE as an anti-cancer drug delivery system.
\end{abstract}

Keywords: Self assembling nanoemulsions; Paclitaxel; Pancreatic; Breast and colon cancer cell lines; Cell proliferation

Citation: M. Bagul et al.. In vitro Evaluation of Antiproliferative Effects of Self-assembling Nanoemulsion of Paclitaxel on various Cancer Cell Lines. Nano Biomed Eng. 2010, 2(2), 100-108. DOI: 10.5101/nbe.v2i2.p100-108.

\section{Introduction}

Current statistics suggest that cancer still remains one of the main causes of death in North America [1-4]. While chemotherapy is widely used for the treatment of various cancers, often times, the higher mortality rates are more associated with the adverse side effects of the intervention rather than the cancer itself [5-7]. These high mortality rates and adverse side effects are usually the result of (a) most of the anti-cancer drugs (> 70\%) being lipid soluble and (b) therapeutic doses are often very high. Nanoemulsion-based drug delivery systems can be used to enhance the chemotherapeutic properties of a drug by reducing the particle size of the typical anti-cancer drug formulation up to 100 fold (microns to $20 \mathrm{~nm}$ ) thereby increasing the drug's bioavailability (absorption into the blood stream) and efficacy (inhibition of uncontrolled cell proliferation) [8-11]. One such drug used in breast cancer chemotherapy is paclitaxel $\left(\right.$ Taxol $^{\circledR}$ ) which has very strong antitumor activity, but has low aqueous solubility thus requiring a high therapeutic dose for effectiveness [12-15].

Paclitaxel is an anti-microtubule agent extracted from the needles and bark of the Pacific yew tree taxus brevifolia [12]. It is used in the treatment of advanced ovarian and breast cancer, lung cancer, and head and neck cancers [16, 17]. Instead of causing disassembly of microtubules, paclitaxel forms extremely stable and nonfunctional microtubules, which causes inhibition of many cell functions and the interruption of the cell cycle [18]. Paclitaxel is a potent anticancer drug, but its use is limited because it is a P-glycoprotein substrate associated with drug resistance [19] and its aqueous solubility is poor [12]. Over the years, various formulations of paclitaxel have been made to improve the efficacy of the drug [20]. Efforts to overcome its poor 
aqueous solubility have included the use of Cremophor EL, which is associated with several adverse side effects [21, 22]. As a result, there have been several attempts to develop a Cremophor EL free-formulation including but not limited to the use of Peglyated PGLA-based formulations [23]. The nanoparticulate formulation Abraxane containing albumin is the most recent commercially available preparation of a Cremophor EL-free paclitaxel [24]. Thus nanoemulsion formulations of paclitaxel of differing compositions to optimize the efficacy of paclitaxel, and subsequently reduce adverse side effects seemed plausible.

The toxicity associated with paclitaxel treatment can be non-specifically distributed in the body where it affects both cancerous as well as normal cells, thereby limiting the dose achievable within the tumor and also resulting in suboptimal treatment due to excessive toxicities [22]. Use of drug-loaded nanoparticles or nanoemulsions can enhance the intracellular concentration of the drug as well as bind to specific receptors and then enter the cell bypassing the recognition of Pglycoprotein, one of the main drug resistance mechanisms [19]. However, limitations such as poor oral bioavailability, instability in circulation, inadequate tissue distribution and toxicity still exist [25].

There are various types of nanoformulations used in drug delivery. These include drug delivery systems that are submicron sized particles $(92-200 \mathrm{~nm})$, that can be made using a variety of materials and configurations such as but not limited to micelles, dendrimers, nanoemulsions, liposomes, viruses and organometallic compounds [9, 10, 24, 26, 27].

Our laboratory has developed a self assembling nanoemulsion (SANE) delivery system [patent pending] for drug delivery. Nanoemulsions are a class of stable emulsions formed by monolayers of phospholipids composed of surfactant and oil suspended in water. The nanoemulsions are often referred to as "Approaching Thermodynamic Stability" [25]. Compared to typical suspension preparations which can be thousands of nanometers in size, nanoemulsion delivery systems utilized and reported from our lab [28-32] as well as those of others with particle sizes approximately 100 $\mathrm{nm}$ or less have been shown to increase bioavailability and efficacy of a number of compounds [25, 33, 34].

The concept of zeta potential and how its reduction can be associated with increased efficacy of drug delivery systems has been raised by reports from our lab [30, 33] and others [35-37]. The objective of this study was to develop and evaluate a Cremophor EL-free nanoemulsion formulation paclitaxel that would increase its efficacy and specificity thereby decreasing the adverse side effects commonly associated with this drug treatment, utilizing in vitro studies of breast, pancreatic and colon cancer cell lines.

\section{Materials and Methods}

\subsection{Cell Culture Line, Growth Conditions and Rea- gents}

The human breast cancer cell line MCF-7, pancreatic cell lines PL-45 and P10.05, and the colon cancer cell line CCL-221 were purchased from the American Type Culture Collection (ATCC, Manassas, VA). These cultures of human tumor cell lines were propagated at $37^{\circ} \mathrm{C}$ in $5 \% \mathrm{CO}_{2} / 95 \% \mathrm{O}_{2}$ after the appropriate number of subcultures as indicated by the manufacturer using ATCC-formulated RPMI-1640 Medium and 10\%(v/v) fetal bovine serum (FBS).

\subsection{Nanoemulsion Preparation}

Paclitaxel was purchased from (Sigma Aldrich, St Louis MO). Rice bran oil (Tsuno, Japan) and the surfactant Solutol HS-15 were purchased from (BASF, Germany) respectively. Four milligrams of rice bran oil were weighed in a beaker. The mixture of rice bran oil and Solutol HS-15 was heated and stirred for 5 min using a magnetic stirrer, until the paclitaxel visually appeared to have dissolved in oil @ $50-60{ }^{\circ} \mathrm{C}$. After an equal amount of Solutol HS was added, the mixture was heated and stirred again for $5 \mathrm{~min}$ at $60{ }^{\circ} \mathrm{C}$ until the three components form a homogeneous mixture. Distilled water was added to a final volume of $50 \mathrm{~mL}$ while the mixture was stirred at $60{ }^{\circ} \mathrm{C}$. At this stage it forms an O/W emulsion. During heating when the PIT (or HLB temperature) of the system is reached (65$70{ }^{\circ} \mathrm{C}$, phase inversion zone), the surfactant is in equilibrium with the oil and water phases. Heating and stirring was continued beyond the PIT up to $80^{\circ} \mathrm{C}$. At this temperature the system inverts to a W/O emulsion. The emulsion was cooled to room temperature to obtain an $\mathrm{O} / \mathrm{W}$ emulsion.

\subsection{Encapsulation Efficiency of Nanoemulsion}

Paclitaxel was analyzed by HPLC (Agilent 1100 series, Santa Clara, California, USA). A reverse phase Zorbax C18 column (250 x 4 mm, 5 um) at room temperature was used. The detector wavelength was set at $227 \mathrm{~nm}$ and injection volume was $20 \mu \mathrm{L}$. The mobile phase was a mixture of acetonitrile and water (50:50 $\mathrm{v} / \mathrm{v}$ ) at a flow rate of $1 \mathrm{~mL} / \mathrm{min}$. The nanoemulsion was diluted in $1 \mathrm{~mL}$ of acetonitrile and then further dilutions were made using the mobile phase. A $100 \mu \mathrm{L}$ aliquot was injected into the HPLC for measurement.

\subsection{In Vitro Cytoxicity Assay}

Cell number and viability were assessed using the MTS reagent (Promega Corporation, Madison, Wisconsin USA), according to the manufacturer's instructions. Cultured cells were plated at a density of 5000 cells per well into 96-well, flat-bottomed tissue culture plates. MCF-7 cells were incubated with 0.25 and $0.125 \mu \mathrm{M}$ concentrations of nanoemulsion containing paclitaxel while the PL-45, P10.05 and CCl-221 cells were treated with $3 \mu \mathrm{M}, 1 \mu \mathrm{M}, 0.3 \mu \mathrm{M}, 0.1 \mu \mathrm{M}, 0.030$ 
$\mu \mathrm{M}, 0.010 \mu \mathrm{M}, 0.003 \mu \mathrm{M}, 0.001 \mu \mathrm{M}$ and $0.0003 \mu \mathrm{M}$ concentrations of paclitaxel. Untreated cells and nanoemulsions containing no drug (blank nanoemulsion) were used as controls. After 72 hr incubation, MTS reagent was added and incubated for an additional $2 \mathrm{hr}$ and then the cell plates were measured at a wavelength of $490 \mathrm{~nm}$ using SpectraMAX (Molecular Devices, Sunnyvale, California). Cell inhibition was calculated using the following equation:

Cell Inhibition (\%) $=\left(1-\left(\mathrm{Abs}_{\mathrm{s}} / \mathrm{Abs}_{\mathrm{ctr}}\right)\right) \times 100$

where $A_{b s}$ is the absorbance of the cells tested with the paclitaxel and nanoblank formulations and $\mathrm{Abs}_{\mathrm{ctrl}}$ is the absorbance of untreated cells.

\subsection{Apoptosis assay using the pancreatic cancer}

PL-45 cells were seeded in a tissue culture-treated dish containing a slide with 50,000 cells per plate and cultured at $37^{\circ} \mathrm{C}$ for $24 \mathrm{hr}$. Cells were then incubated for an additional $72 \mathrm{hr}$ with $300 \mathrm{nM}, 30 \mathrm{nM}$ and $15 \mathrm{nM}$ of the nanoemulsion formulations of paclitaxel or blank nanoemulsions. Untreated cells were used as the control. Samples were then fixed by adding $4 \%$ paraformaldehyde made up in PBS for $10 \mathrm{~min}$ to the cell plates containing the slides. Ten $\mu \mathrm{g} / \mathrm{mL}$ of Hoechst dye (Invitrogen, Carlsbad, CA) was added to the fixing step. The samples were then washed twice in PBS. Coverslips were mounted on glass slides which were examined using a fluorescent microscope (Olympus America Inc, Center Valley Pa). Random fields of cells were selected to obtain unbiased distributions.

\subsection{Colony Formation Assay}

Colony formation properties of tumor cells were assayed using the clonogenic survival assay. PL-45 cells were seeded in $10 \mathrm{~cm}$ tissue culture-treated plates at a suitable density for $24 \mathrm{hr}$. The cells were then treated with $0.03 \mu \mathrm{M}$ and $0.1 \mu \mathrm{M}$ of paclitaxel as a nanoemulsion formulation or blank nanoemulsion. Untreated cells were used as control. After $48 \mathrm{hr}$, the treated cells were trypsinized, counted and plated in 6-well dishes at suitable concentrations. The cells were cultured for 10 days. After 10 days of incubation at $37^{\circ} \mathrm{C}$ under $5 \% \mathrm{CO}_{2} / 95 \% \mathrm{O}_{2}$, the cells were fixed and stained with $1 \%$ crystal violet (Sigma Aldrich, St Louis MO).

\subsection{Statistical Methods}

SigmaStat software was used for all statistical evaluations (Jandel Scientific, San Rafael, CA, USA) [38]. A repeated measures one-way analysis of variance (RM ANOVA) was used to analyze the data. When statistical significance was found by ANOVA, the StudentNewman-Keuls separation of means was used to determine differences. All values are expressed as mean \pm SD and all measured parameters underwent statistical analyses using the student's " $t$ " test. Statistical significance was set at the minimum $\mathrm{p}<0.05$.

\section{Results}

\subsection{Nanoemulsion characterization and encapsula- tion efficiency}

The initial particle size Z-Average of the paclitaxel suspension contained peaks greater than $2000 \mathrm{~nm}$ which were reduced to $20 \mathrm{~nm}$ after SANE preparation (Fig.1). The polydisperity index (PDI) which is defined by the average molecular weight $(\mathrm{Mw})$ divided by the average number of molecular weight particles $(\mathrm{Mn})$ was 0.1 for the paclitaxel nanoemulsion formulation and was greater than 1 for the paclitaxel suspensions. Relative to the increased zeta potential of the paclitaxel suspended in DMSO suspensions $(-15 \mathrm{mV})$ the paclitaxel nanoemulsion formulations demonstrated a reduced zeta potential $(1 \mathrm{mV})$, i.e., decreased negative charge [less anionic and more cationic]. The blank nanoemulsion showed neutral or slightly negative $(-0 . \mathrm{mV})$ zeta potential. The particle size, polydispersity index and zeta potential of the paclitaxel nanoemulsion formulation remained unchanged (stable) compared to the paclitaxel suspension after one month when stored at $4{ }^{\circ} \mathrm{C}$ (data not shown). The HPLC analysis used to determine encapsulant efficiency indicated that $79 \%$ of paclitaxel was entrapped in the nanoemulsion. The encapsulation efficiency of less than $100 \%$ maybe to either disruption of the primary W/O phase or due to leaching out of material from the inner aqueous phase.

\subsection{Effect of nanoemulsion of paclitaxel on cell pro- liferation activity}

MCF-7 breast cancer, CCL-221 colon cancer and P10.05 pancreatic cancer cell lines were treated with various concentrations of the drug encapsulated in the nanoemulsion and the cells were incubated at $37^{\circ} \mathrm{C}$ under $5 \% \mathrm{CO}_{2} / 95 \% \mathrm{O}_{2}$ for 72 hrs. Although, CCL-221, PL-45 and P10.05 showed 80\% cell growth inhibition when treated with the blank nanoemulsion and nanoemulsions encapsulating paclitaxel at the high concentration of $3000 \mathrm{nM}$ and $1000 \mathrm{nM}$, nevertheless, paclitaxel-containing nanoemulsions effectively inhibited cell growth at the much lower concentrations of $300 \mathrm{nM}$, $100 \mathrm{nM}, 30 \mathrm{nM}$ and $10 \mathrm{nM}$ compared to the blank nanoemulsion in CCL-221, PL-45, and P10.05, suggesting a very significant drug effect over carrier cytotoxicity. As shown in Figure 2, the MCF-7 breast cancer cell line exhibited $80 \%$ growth inhibition at $0.25 \mu \mathrm{M}$ and $0.125 \mu \mathrm{M}$ when treated with nanoemulsion containing paclitaxel. The blank nanoemulsion showed minimal to no anti-cell proliferative activity. Nanoemulsions containing paclitaxel effectively inhibited cell growth of CCL-221 by $60 \%(\mathrm{p}<0.05)$ over blank nanoemulsion when treated at 


$\begin{array}{rllll} & & \text { Diam. }(\mathrm{nm}) & \% \text { intensity } & \text { Width }(\mathrm{nm}) \\ \text { Z-Average (d.nm): } 20.49 & \text { Peak 1: } & 21.95 & 100.0 & 5.711 \\ \text { Pdl: } 0.071 & \text { Peak 2: } & 0.000 & 0.0 & 0.000 \\ \text { Intercept: } 0.970 & \text { Peak 3: } & 0.000 & 0.0 & 0.000\end{array}$

Result quality: Good

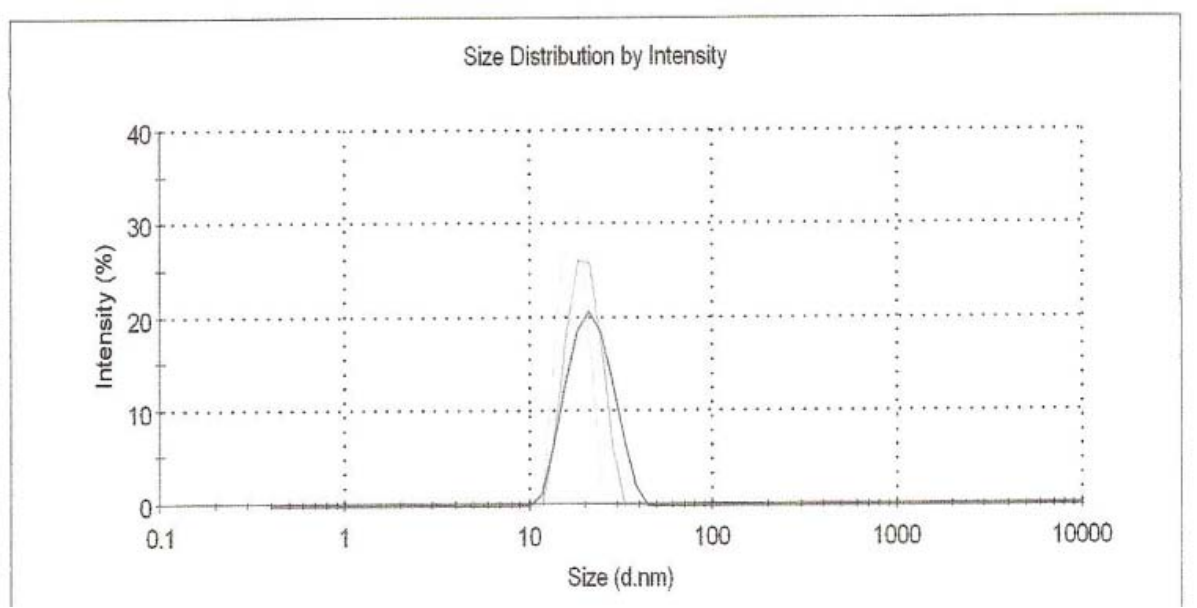

Figure 1. Z-average size distribution of the nanoemulsion of paclitaxel using dynamic laser light scattering particle size analysis showing that the particle size of the nanoemulsion containing paclitaxel is reduced to $20 \mathrm{~nm}$.

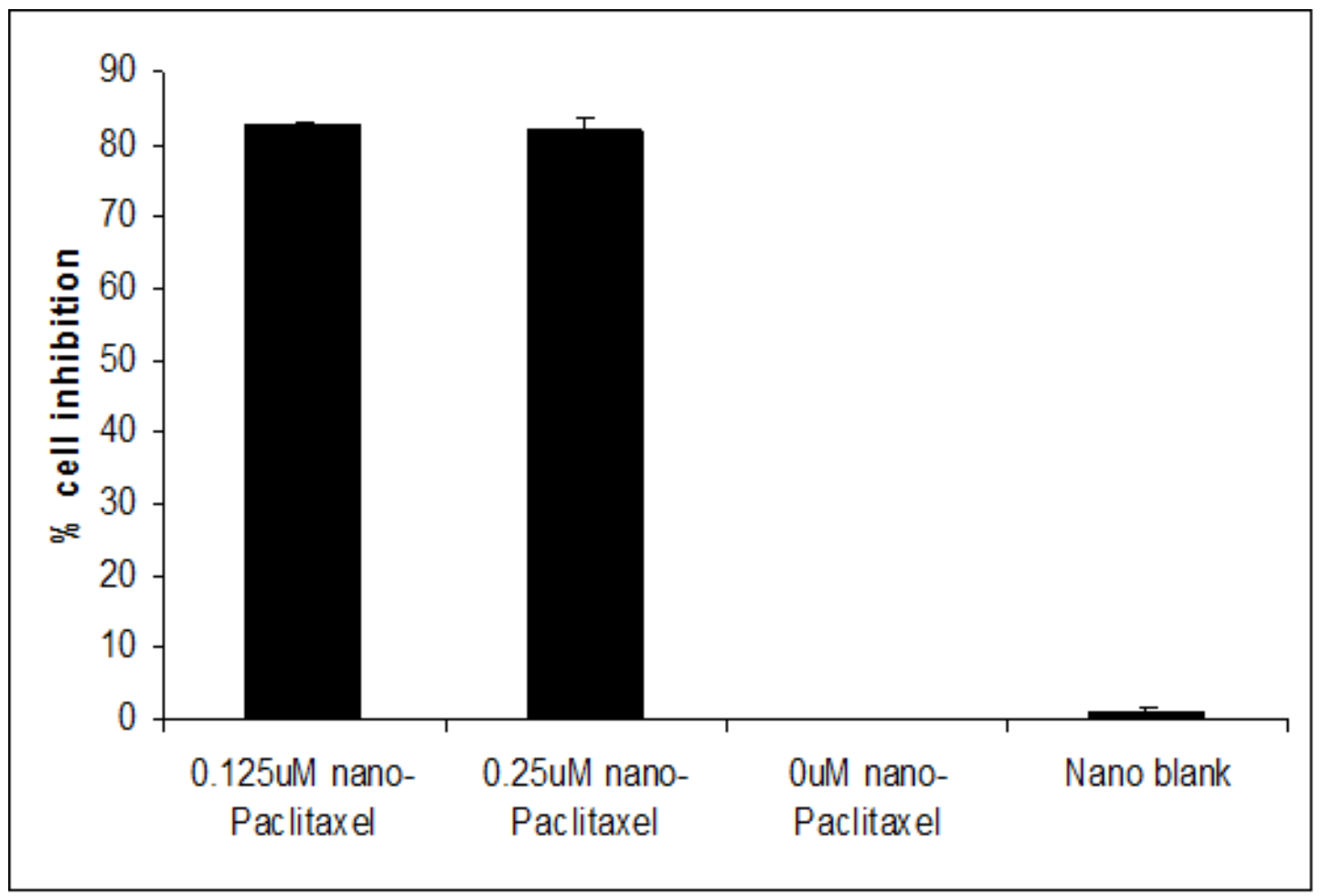

Figure 2. Determination of in vitro cell cytotoxicity on MCF-7 cells. MCF-7 exhibited 80 \% decrease in cell proliferation after treatment with $0.125 \mu \mathrm{M}$ and $0.25 \mu \mathrm{M}$ of nanoemulsion containing paclitaxel when compared to blank nanoemulsion and untreated cells. 

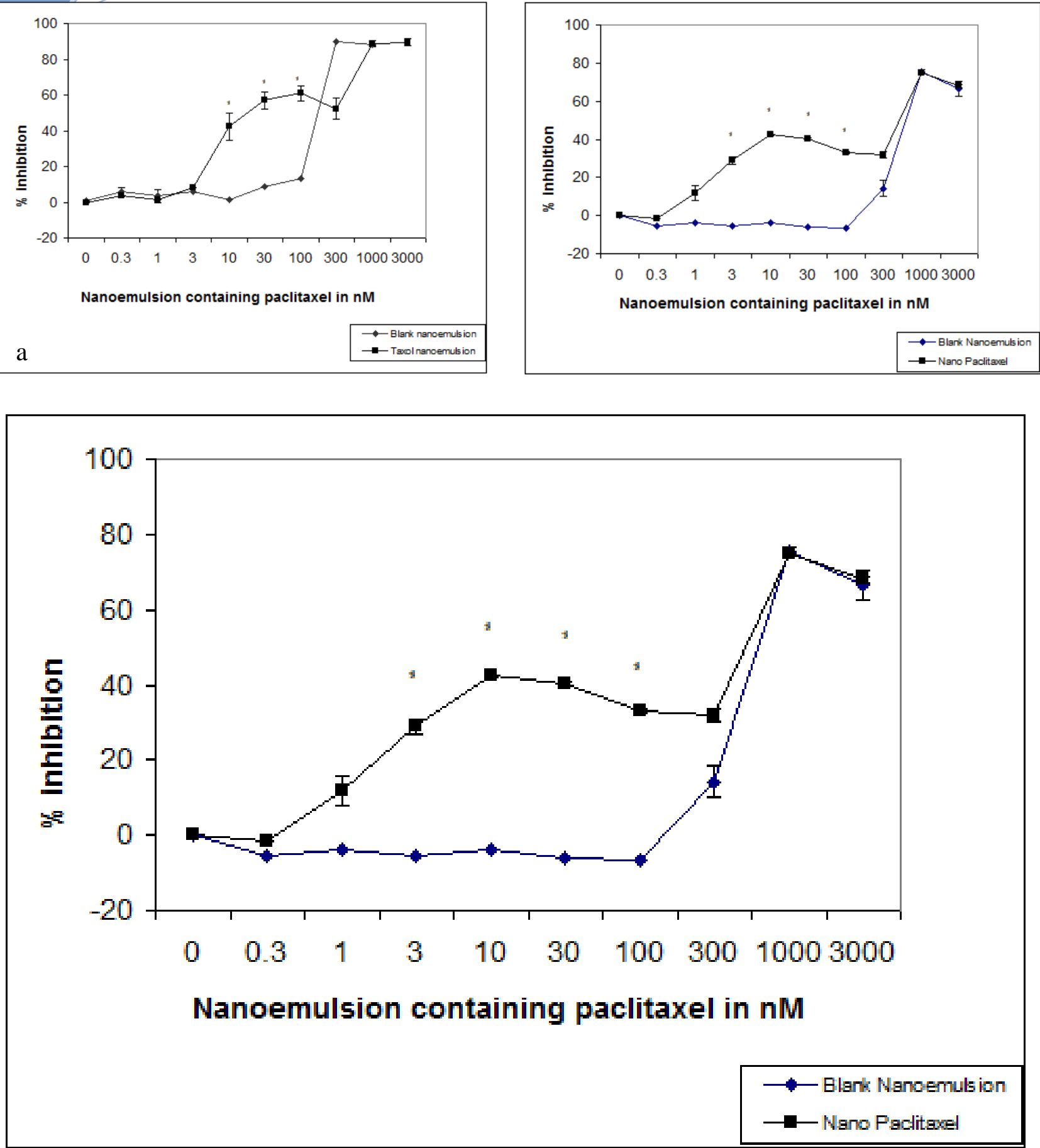

Figure 3. Antiproliferative effects of (a) $60 \%$ on CCL-21 when treated with $300 \mathrm{nM}, 100 \mathrm{nM}$, 30nM and 10nM of paclitaxel encapsulated in nanoemulsion (b) $50 \%$ on PL-45 when treated with $300 \mathrm{nM}, 100 \mathrm{nM}$, 30nM and 10nM of paclitaxel encapsulated in nanoemulsion (c) $60 \%$ when treated with 300nM, 100nM, 30nM and 10nM of paclitaxel encapsulated in nanoemulsion on P10.05 was observed when cells were treated for 72 hours. Untreated cells were used as control. Error bars represent the standard deviation of the mean for two sets of independent experiments done in triplicates. Statistical analysis by one way ANOVA and student t-test: ${ }^{*} \mathrm{p}<0.05$ as compared to blank nanoemulsion.

$300 \mathrm{nM}, 100 \mathrm{nM}, 30 \mathrm{nM}$ and $10 \mathrm{nM}$. (Fig. 3a). As shown in Fig. 3b PL-45 cells were significantly inhibited by $50 \%(\mathrm{p}<0.05)$ at concentrations as low as 30 and $10 \mathrm{nM}$ when treated with nanoemulsion containing paclitaxel. A sustained decrease of $60 \%(\mathrm{p}<0.05)$ at $300 \mathrm{nM}, 100 \mathrm{nM}, 30 \mathrm{nM}, 10 \mathrm{nM}, 3 \mathrm{nM}$ in the cell growth was observed when P10.05 cells were treated with nanoemulsions containing paclitaxel. (Fig. 3c). 

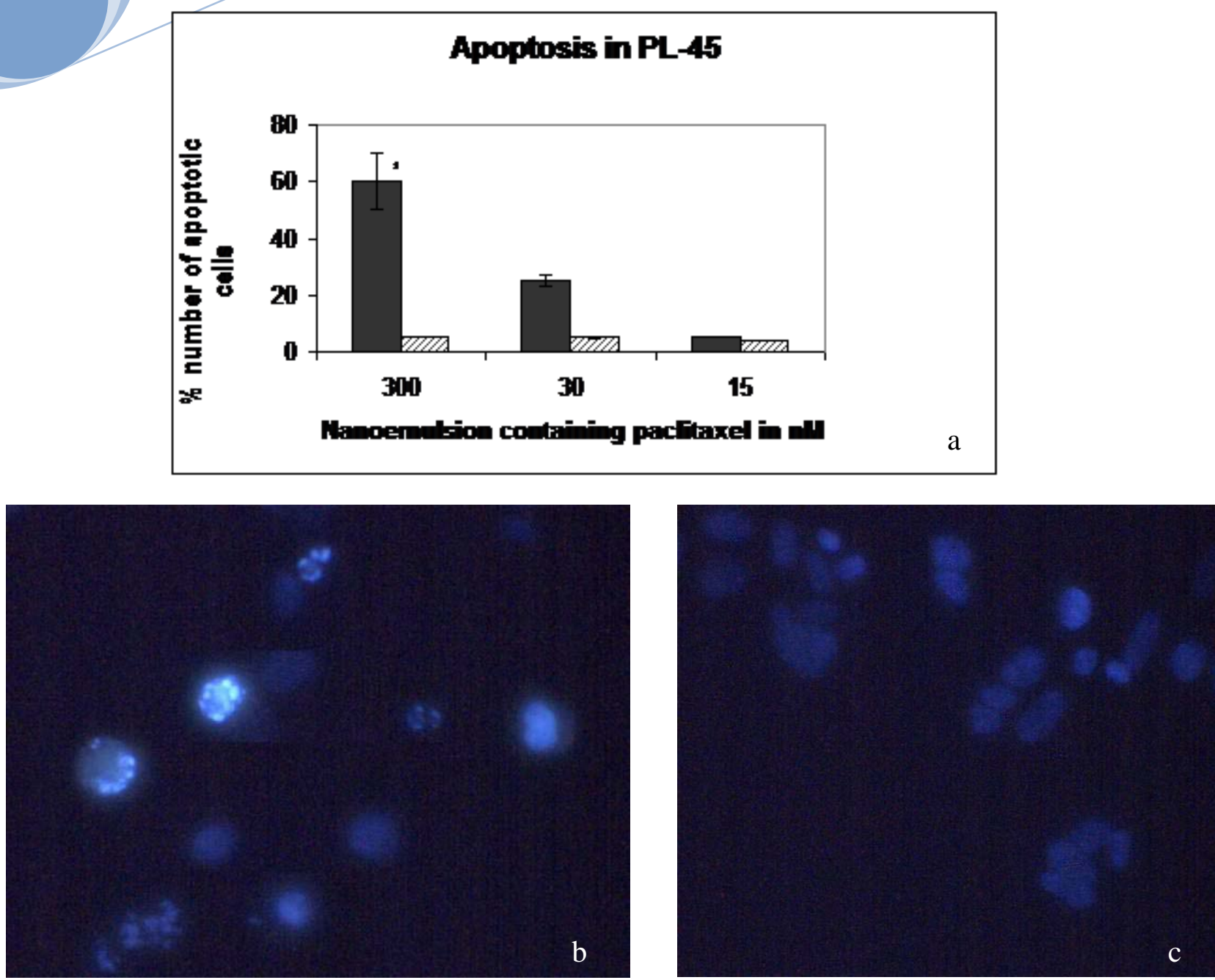

Figure 4. Apoptosis assay (a) Percent number of apoptotic cells staining of PL-45 cells after 48 hours of incubation with nanoemulsions containing $300 \mathrm{nM}, 30 \mathrm{nM}$ and $15 \mathrm{nM}$ of paclitaxel and blank nanoemulsion. ${ }^{*} \mathrm{p}<0.05$ as compared to blank nanoemulsion (b) Represents the visualization of apoptosis using Hoechst staining on PL-45 cells treated when treated with $300 \mathrm{nM}$ of nanoemulsion containing paclitaxel and (c) blank nanoemulsion. A total number of 100 cells were counted and the results were based on two random fields picked on the slide in two different independent experiments. The apoptotic bodies were counted from random fields on the slides. Blank nanoemulsion was used as a control. The percent apoptotic cells were based on the number of cells counted by visualization of the apoptotic cells. ${ }^{*} \mathrm{p}<0.05$ as compared to nano blank.

\subsection{Apoptosis Assay}

To determine whether paclitaxel-containing nanoemulsion had apoptotic activity, PL-45 cells were treated with different concentrations of paclitaxel; the blank nanoemulsion was used as a control in order to reduce or eliminate any effects caused by the blank nanoemulsion itself. The results revealed that nanoemulsion of paclitaxel-treated cells showed $60 \%$ $(\mathrm{P}<0.05)$ apoptotic activity demonstrating a 12 -fold increase in apoptotic activity as compared to $3 \%$ apoptotic activity of the blank nanoemulsion control itself (Figure 3a) when treated with $300 \mathrm{nM}$ of paclitaxel encapsulated in the nanoemulsion. The nuclei of untreated cells showed homogenous fluorescence with no evidence of segmentation and fragmentation after Hoechst staining. Interestingly, exposure of cells to nanoemulsions containing paclitaxel led to segregation of cell nuclei into segments, which indicates breakdown in chromatin followed by DNA condensation, the classical signs of apoptosis. A special note should be made of the fact that the blank nanoemulsion demonstrated minimal apoptotic effects.

\subsection{Colony formation assay}

Colonies formed after 10days were counted manually. A rapid growth in forming larger colonies was observed in the wells treated with blank nanoemulsions. In contrast, no larger colony formation was observed in cells treated with nanoemulsions containing paclitaxel as shown in Fig.5, where the numbers of colonies formed in wells treated with drug free nanoemulsion and untreated control were significantly more $(75 \%)$ than the wells treated with Nan emulsion of paclitaxel. 


\section{Discussion}

Over the past decade, various delivery methods and drug formulations for cancer drugs have been used to minimize drug toxicity, improve therapeutic effects and broaden the therapeutic window of the drug [39, 40]. Many anticancer chemotherapeutic drugs are water insoluble and highly toxic limiting their clinical efficacy $[19,41]$. Accordingly, organic solvents are used for drug delivery of cancer drugs that overcome the insolubility associated with these hydrophobic drugs [42]. But additional toxicities are associated with these organic solvents. Therefore, there is a need for novel formulations, which (a) convert lipid soluble drugs to stable water dispersion and reduce the side effects caused by the drug itself and also the vehicles and (b) increase the therapeutic efficacy of the drugs [8, 43]. Novel methods such as nanodelivery systems would also improve biodistribution of cancer drugs and the pharmacokinetic profile [25].

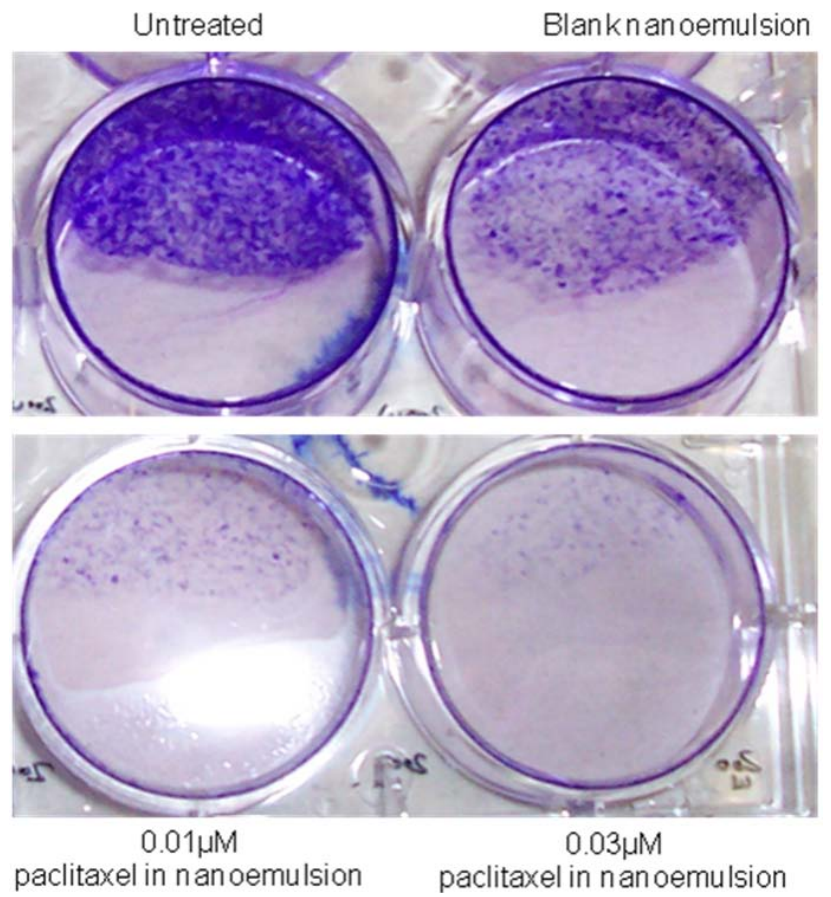

Figure 5. Colony formation assay: The effect of $0.01 \mu \mathrm{M}$ and $0.03 \mu \mathrm{M}$ nanoemulsion encapsulating paclitaxel, blank nanoemulsion and no treatment on colony formation properties of PL-45 cells after 48hr treatment of the drug. Compared to nanoblank and untreated controls, a $75 \%$ decrease in colony formation was observed.

Paclitaxel is one such anti-neoplastic drug that is used in cancer therapy known for its aqueous insolubility $[16,16]$, which, as a result, is associated with increased binding to blood protein limiting its ability in treatment of solid tumors [10, 26]. Currently, paclitaxel is administered in two forms, one as Taxol that is formulated by dissolving the mixture of dehydrated etha- nol and Cremophor EL and Abraxane, which is an albumin, based nanoparticle formulation [23, 44]. Studies have indicated that most of the toxicity associated with Taxol is from the surfactant Cremophor-EL [20, 45, 46].

In this study, we have developed a nanoemulsion formulation for delivery of paclitaxel, which is Cremophor EL free. The $20 \mathrm{~nm}$ particle size of this nanoemulsion of paclitaxel is up to 50 fold less than the conventional drug suspensions, which is one of the optimal characteristics of a carrier-mediated drug delivery. Nanoemulsions containing paclitaxel exhibited excellent stability over a month (data not shown), which is an important parameter in a drug delivery system. In agreement with paclitaxel being one of the fundamental anti tumor agent used in treatment of early or advanced breast cancer therapy [13, 15, 47] we have demonstrated consistent $80 \%$ inhibition achieved in a breast cancer cell line when treated with $25 \mu \mathrm{M}$ and $125 \mu \mathrm{M}$ of paclitaxel encapsulated in nanoemulsions (Fig 2), but at significantly less concentrations than traditionally utilized (40\%) (data not shown). Moreover, a sustained inhibition of $50-60 \%$ was achieved at $300 \mathrm{nM}, 100 \mathrm{nM}$, $30 \mathrm{nM}$ and $10 \mathrm{nM}$ in colon and pancreatic cancer cell lines when treated with paclitaxel encapsulated in the nanoemulsion. Most interestingly, this unique nanoemulsion formulation of paclitaxel showed enhanced anti-cell proliferative capacity and effective apoptotic properties on pancreatic cancer cells compared to the blank nanoemulsion which revealed only minimal antiproliferative and apoptotic effects. Taken together, the cell proliferation inhibitory abilities of nano-emulsions containing paclitaxel and colony formation clearly indicate the in vitro efficacy of the nanoemulsion containing paclitaxel when compared to blank nanoemulsion. Accordingly, this novel formulation can provide a distinct framework for safe and efficient drug delivery, especially for poorly soluble drugs. These findings will require additional studies involving the evaluation of this SANE formulation of paclitaxel in animal models such as the immune-compromised xenograft nude mouse.

\section{Acknowledgements}

The authors would like to thank the graduate students and staff at the Center of Health and Disease Research at UMass Lowell for their support and assistance in conducting the study.

\section{References}

1. Jemal A, Siegel R, Ward E, Murray T, Xu J, Smigal C, Thun MJ: Cancer statistics, 2006. CA Cancer J Clin 2006, 56(2):106-130. doi:10.3322/canjclin.56.2.106

2. Jemal A, Siegel R, Ward E, Hao Y, Xu J, Murray T, Thun MJ: Cancer statistics, 2008. CA Cancer J Clin 2008, 58(2):71-96. doi:10.3322/CA.2007.0010 
3. Jemal A, Siegel R, Ward E, Murray T, Xu J, Thun MJ: Cancer statistics, 2007. CA Cancer J Clin 2007, 57(1):4366. doi:10.3322/canjclin.57.1.43

4. Jemal A, Siegel R, Ward E, Hao Y, Xu J, Thun MJ: Cancer statistics, 2009. CA Cancer J Clin 2009, 59(4):225249. doi:10.3322/caac.20006

5. Newcomb PA, Carbone PP: Cancer treatment and age: patient perspectives. J Natl Cancer Inst 1993, 85(19):15801584. doi:10.1093/jnci/85.19.1580

6. Carter SK: Integration of chemotherapy into combined modality treatment of solid tumors VII. Adenocarcinoma of the breast. Cancer Treat Rev 1976, 3(3):141174. doi:10.1016/S0305-7372(76)80020-5

7. Carter SK, Comis RL: The integration of chemotherapy into a combined modality approach for cancer treatment. VI. Pancreatic adenocarcinoma. Cancer Treat Rev 1975, 2(3):193-214. doi:10.1016/S0305-7372(75)80003-X

8. Wang MD, Shin DM, Simons JW, Nie S: Nanotechnology for targeted cancer therapy. Expert Rev Anticancer Ther 2007, 7(6):833-837. doi:10.1586/14737140.7.6.833

9. Zhang R, Wang X, Wu C, Song M, Li J, Lv G, Zhou J, Chen C, Dai Y, Gao F, Fu D, Li X, Guan Z, Chen B: Synergistic enhancement effect of magnetic nanoparticles on anticancer drug accumulation in cancer cells. Nanotechnology 2006, 17(14):3622-3626. doi:10.1088/0957-448 4/17/14/043

10. Yang YY, Wang Y, Powell R, Chan P: Polymeric coreshell nanoparticles for therapeutics. Clin Exp Pharmacol Physiol 2006, 33(5-6):557-562. doi:10.1111/j.14401681.2006.04408.x

11. Wang X, Wang Y, Chen ZG, Shin DM: Advances of cancer therapy by nanotechnology. Cancer Res Treat 2009, 41(1):1-11. doi:10.4143/crt.2009.41.1.1

12. Gotaskie GE, Andreassi BF: Paclitaxel: a new antimitotic chemotherapeutic agent. Cancer Pract 1994, 2(1):27-33.

13. Hortobagyi GN, Holmes FA: Single-agent paclitaxel for the treatment of breast cancer: an overview. Semin Oncol 1996, 23(1):4-9.

14. Rivera E, Holmes FA, Frye D, Valero V, Theriault RL, Booser D, Walters R, Buzdar AU, Dhingra K, Fraschini G, Hortobagyi GN: Phase II study of paclitaxel in patients with metastatic breast carcinoma refractory to standard chemotherapy. Cancer 2000, 89(11):2195-2201. doi:10.1 002/1097-0142(20001201)89:11<2195::AID-CN CR7>3.0.CO;2-W

15. Holmes FA, Walters RS, Theriault RL, Forman AD, Newton LK, Raber MN, Buzdar AU, Frye DK, Hortobagyi GN Phase II trial of taxol, an active drug in the treatment of metastatic breast cancer. J Natl Cancer Inst 1991, 83(24):1797-1805. doi:10.1093/jnci/83.24.1797-a

16. Foa R, Norton L, Seidman AD: Taxol (paclitaxel): a novel anti-microtubule agent with remarkable anti-neoplastic activity. Int J Clin Lab Res 1994, 24(1):6-14. doi:10.1 007/BF02592403

17. Guppy AE, Nathan PD, Rustin GJ: Epithelial ovarian cancer: a review of current management. Clin Oncol (R Coll Radiol) 2005, 17(6):399-411. doi:10.1016/j.clon.2005.0 $\underline{5.009}$

18. Yeung TK, Germond C, Chen X, Wang Z: The mode of action of taxol: apoptosis at low concentration and necrosis at high concentration. Biochem Biophys Res Commun 1999, 263(2):398-404. doi:10.1006/bbrc.1999.1375

19. Singla AK, Garg A, Aggarwal D: Paclitaxel and its formulations. Int J Pharm 2002, 235(1-2):179-192. doi:10.101 6/S0378-5173(01)00986-3

20. Gelderblom H, Verweij J, Nooter K, Sparreboom A: Cremophor EL: the drawbacks and advantages of vehicle se- lection for drug formulation. Eur J Cancer 2001, 37(13):1590-1598. doi:10.1016/S0959-8049(01)00171-X

21. Rowinsky EK, Eisenhauer EA, Chaudhry V, Arbuck SG, Donehower RC: Clinical toxicities encountered with paclitaxel (Taxol). Semin Oncol 1993, 20(4):1-15.

22. Danhier F, Lecouturier N, Vroman B, Jerome C, Marchand-Brynaert J, Feron O, Preat V: Paclitaxel-loaded PEGylated PLGA-based nanoparticles: in vitro and in vivo evaluation. J Control Release 2009, 133(1):11-17. doi:1 0.1016/j.jcon rel.200 8.09.086

23. Miele E, Spinelli GP, Tomao F, Tomao S: Albumin-bound formulation of paclitaxel (Abraxane ABI-007) in the treatment of breast cancer. Int J Nanomedicine 2009, 4:99105.

24. Sinha R, Kim GJ, Nie S, Shin DM: Nanotechnology in cancer therapeutics: bioconjugated nanoparticles for drug delivery. Mol Cancer Ther 2006, 5(8):19091917. doi:10.1158/1535-7163.MCT-06-0141

25. Kotyla T, Kuo F, Moolchandani V, Wilson T, Nicolosi R: Increased bioavailability of a transdermal application of a nano-sized emulsion preparation. Int J Pharm 2008, 347(12):144-148. doi:10.1016/j.ijpharm.2007.06.045

26. Yang T, Cui FD, Choi MK, Lin H, Chung SJ, Shim CK, Kim DD: Liposome formulation of paclitaxel with enhanced solubility and stability. Drug Deliv 2007, 14(5):301-308. doi:10.1080/10717540601098799

27. Nobs L, Buchegger F, Gurny R, Allemann E: Biodegradable nanoparticles for direct or two-step tumor immunotargeting. Bioconjug Chem 2006, 17(1):139-145. doi:1 0.1021/bc050137k

28. Kuo F, Subramanian B, Kotyla T, Wilson TA, Yoganathan $\mathrm{S}$, Nicolosi RJ: Nanoemulsions of an anti-oxidant synergy formulation containing gamma tocopherol have enhanced bioavailability and anti-inflammatory properties. Int $\mathrm{J}$ Pharm 2008, 363(1-2):206-213. doi:10.1016/j.ijpharm.200 $\underline{8.07 .022}$

29. Subramanian B, Kuo F, Ada E, Kotyla T, Wilson T, Yoganathan S, Nicolosi R: Enhancement of antiinflammatory property of aspirin in mice by a nano- emulsion preparation. Int Immunopharmacol 2008, 8(11):15331539. doi:10.1016/j.intimp.2008.06.009

30. Shea T, Ortiz D, Nicolosi R, Kumar R, Watterson A: Nanosphere-mediated delivery of vitamin $\mathrm{E}$ increases its efficacy against oxidative stress resulting from exposure to amyloid beta. J Alzheimer's Dis 2005, 7(4):297-301.

31. Hancock A, Nakuci E, Nicolosi R, Shea T: An antitoxidant formulation that induces differentiation of neuroblastoma in culture. Neurosci Res Commun 2003, 33(1):7376. doi:10.1002/nrc.10082

32. Tagne JB, Kakumanu S, Nicolosi RJ: Nanoemulsion Preparations of the Anticancer Drug Dacarbazine Significantly Increase Its Efficacy in a Xenograft Mouse Melanoma Model. Mol Pharm 2008,

33. Tagne JB, Kakumanu S, Ortiz D, Shea T, Nicolosi RJ: A nanoemulsion formulation of tamoxifen increases its efficacy in a breast cancer cell line. Mol Pharm 2008, 5(2):280-286. doi:10.1021/mp700091j

34. Chono S, Tauchi Y, Morimoto K: Influence of Particle Size on the Distributions of Liposomes to Atherosclerotic Lesions in Mice. Drug Dev Ind Pharm 2006, 32(1):125135. doi:10.1080/03639040500390645

35. Gaumet M, Vargas A, Gurny R, Delie F: Nanoparticles for drug delivery: The need for precision in reporting particle size parameters. European Journal of Pharmaceutics and Biopharmaceutics 2008, 69(1):1-9. doi:10.1016/j.ejpb.200 $\underline{7.08 .001}$ 
36. 36. Lee M, Lim S, Kim C: Preparation, characterization and in vitro cytotoxicity of paclitaxel- loaded sterically stabilized solid lipid nanoparticles. Biomaterials 2007, 28(12):2137-2146. doi:10.1016/j.biomaterials.2007.01.014

37. Snedecor GW, Cochran WG, Ames IA.: Statistical methods. The Iowa State University Press; 1980.

38. Hait WN, Hambley TW: Targeted cancer therapeutics. Cancer Res 2009, 69(4):1263-7; discussion 1267. doi:10.1 158/0008-5472.CAN-08-3836

39. Bawarski WE, Chidlowsky E, Bharali DJ, Mousa SA: Emerging nanopharmaceuticals. Nanomedicine 2008, 4(4):273-282.

40. Siddiqui IA, Adhami VM, Bharali DJ, Hafeez BB, Asim M, Khwaja SI, Ahmad N, Cui H, Mousa SA, Mukhtar H: Introducing nanochemoprevention as a novel approach for cancer control: proof of principle with green tea polyphenol epigallocatechin-3-gallate. Cancer Res 2009, 69(5):1712-1716. doi:10.1158/0008-5472.CAN-08-3978

41. Brayton CF: Dimethyl sulfoxide (DMSO): a review. Cornell Vet 1986, 76(1):61-90.

42. Cho K, Wang X, Nie S, Chen ZG, Shin DM: Therapeutic nanoparticles for drug delivery in cancer. Clin Cancer Res 2008, 14(5):1310-1316. doi:10.1158/1078-0432.CCR-07$\underline{1441}$

43. Sykes E, Woodburn K, Decker D, Kessel D: Effects of Cremophor EL on distribution of Taxol to serum lipoproteins. Br J Cancer 1994, 70(3):401-404.

44. Nornoo AO, Osborne DW, Chow DS: Cremophor-free intravenous microemulsions for paclitaxel I: formulation, cytotoxicity and hemolysis. Int J Pharm 2008, 349(12):108-116. doi:10.1016/j.ijpharm.2007.07.042

45. Gelderblom H, Verweij J, van Zomeren DM, Buijs D, Ouwens L, Nooter K, Stoter G, Sparreboom A: Influence of Cremophor El on the bioavailability of intraperitoneal paclitaxel. Clin Cancer Res 2002, 8(4):1237-1241.

46. Hortobagyi GN, Holmes FA, Theriault RL, Buzdar AU: Use of Taxol (paclitaxel) in breast cancer. Oncology 1994, 51 Suppl 1:29-32. doi:10.1159/000227413

Received 16 May, 2010; accepted 20 June, 2010; published online 26 June, 2010.

Copyright: (C) 2010 M. Bagul et al. This is an open access article distributed under the terms of the Creative Commons Attribution License, which permits unrestricted use, distribution, and reproduction in any medium, provided the original author and source are credited. 